\title{
Join the club: a modest proposal to increase availability of donor organs
}

\author{
Rupert Jarvis University College of Swansea, Swansea
}

\begin{abstract}
The shortage of suitable donor organs is the most significant single limiting factor in transplant programmes. More lives could be saved or immeasurably improved if more organs were available. I look at two traditional solutions to the shortfall, and suggest that they are ineffective and/or offensive, and consider the features common to any answer to the problem. I then suggest a third solution: that admission to future transplant lists be conditional on registration as a potential organ donor, outlining its benefits, and defending it against one possible objection.
\end{abstract}

I.

In a health service where rationing has become a fact of life, nowhere is the problem of demand outstripping supply more obvious than in the field of organ transplants. For reasons not entirely obvious, despite the fact that the majority of Britons believe that cadaver donation of organs is both ethically acceptable and practically desirable, still only a minority actually possess donor cards, and even fewer carry them:

'a Gallup poll for the British Kidney Patient Association, quoted in The Guardian (9.5.90), found that 73 per cent of respondents would agree to their kidneys being used for transplantation, although only 27 per cent actually had a donor card and only seven per cent were carrying one on them at the time' (1).

The problem is not that there are insufficient numbers of organs potentially suitable for transplantation, but that these organs, far from being made available for transplant, are destroyed, leaving those in need of a transplant either to improve their quality of life, as in the case of a kidney transplant, or as a life-saving measure, in the case of a heart transplant,

\section{Key words}

Donor organs; justice; transplants; rationing. still waiting. At one and the same time, the organs necessary to save or immeasurably improve actual, identifiable lives (2) are themselves in existence, and yet people are dying for the want of them: 'Organ supply is the major limiting factor in organ transplantation' (3). That is to say, the number of lives saved as a result of transplants could - if donor organs were more readily available to transplant surgeons - be considerably higher.

Nor is the problem a medical one: since the introduction of immunosuppressive drugs such as cyclosporin, which vastly lessen the dangers of rejection, the actual process of transplantation is not a particularly unusual or dangerous one. Although the operations are long and complex, they are, at least in centres largely dedicated to such procedures, relatively routine. In the best $\mathrm{B}$-movie tradition, we have the technology.

The upshot of this is clear enough: given that demand for resources exceeds the (presently available) supply, there is a need to ration the available resources by prioritising demand - to decide who is to receive the benefits offered by a transplant operation, and who is to go without. Such overt rationing, particularly when it is applied to identifiable individual patients, is often held to be highly distasteful both by health care professionals and by the lay public, since it seems to sit uneasily alongside a duty to care. It is not my present purpose to examine the interesting question of whether a health care professional can or should act as a gatekeeper to resources. Instead, I shall look briefly at some problems associated with the current parameters by reference to which transplant organ availability is rationed, and examine two suggested remedies to the current shortage of organs available for transplant. I shall then suggest some desiderata of any proposed solution to the problem, and apply them to one further possible solution.

\section{II.}

There is a familiar suggestion that any finite health care resources for which there is excessive demand could be rationed by one or more of the more or less 
quantifiable, non-medical parameters, such as age, desert, or social utility. The latter two are, fortunately, not often suggested except in the context of a thought experiment, while the former is more usually dressed up in the guise of ability to benefit, which I discuss below. I take it that there is little doubt that it would be unjust to ration access to transplant services by such factors as desert or social utility, or any other non-medical category, such as class, ethnic origin (4), or gender. What would be unjust about a policy that used such criteria to ration is that it would violate the Aristotelian principle of distributive justice, that only those cases that are relevantly dissimilar should be treated differently. It is abundantly clear that class or social utility are utterly irrelevant to considerations of prioritising demand for transplant services.

If such non-medical criteria are of no use in rationing, then what of the traditional concept of ability to benefit from the treatment? Even a cursory review of the literature reveals that of the various criteria, this is the one most nearly agreed upon, and it seems reasonable that this should be so: to take an extreme example, there is neither point nor justification in treating someone for a condition which is not present. More realistically, it seems reasonable to suggest that those patients whose chance of survival is significantly lower for one reason or another, for example the existence of another condition which prejudices their chance of surviving the operation, should not receive as high a priority in the queue for donor organs as those whose ability to benefit is greater. This is to say that an assessment of the relationship between a proposed transplant's risks and benefits to an individual could be used to determine access to transplant services.

\section{The 'free rider'}

While this looks like an elegant and reasonable solution to the rationing problem, it is not. As a means of ordering a queue it has a certain merit, particularly that it takes account only of those differences which are relevant to the particular case. However, perhaps unfortunately from the point of view of finding a tool for rationing, there are still many, many more people who could benefit somewhat from a transplant operation than there are available donor organs for them. The problem of the inequality between supply and demand, then, is not to be resolved simply by applying the criterion of the patient's ability to benefit. It is inadequate as a tool of rationing since it allows far too many in through the gates. While it may serve to reduce the total number of those waiting for transplants by a small amount, it leaves us a long way from a satisfactory account of how to ration donor organs.

A third problem with the current system by which donor organs are rationed is that it takes no account of, indeed it encourages, the 'free rider': the individual who hopes to benefit from the co-operation of others even though he does not himself contribute $\frac{c}{\infty}$ to the socially desired end. Although it is in each $\frac{\varrho}{m}$ individual's interest that donor organs should be $\vec{F}$ available, it is in nobody's interests to make his/her own organs available: the choice to donate post $\stackrel{\Rightarrow}{\Rightarrow}$ mortem is an entirely altruistic one. We therefore $\stackrel{\vec{S}}{+}$ have the current situation where demand is not? matched by supply, and individual patients who $\frac{\text {. }}{n}$ could benefit from a transplanted organ are denied $\frac{\bar{\omega}}{\bar{\sigma}}$ that treatment owing to a lack of suitable organs $\stackrel{\varnothing}{\varrho}$ available for transplant.

\section{III.}

If that is the problem, what have been the suggested solutions? Two main strands have emerged, one of $\overline{3}$ which has received little support. They can be labelled respectively opting-out, and cash payments for organs.

The first proposed solution has already been $\vec{\bullet}$ implemented in a number of countries, including응 Denmark, Austria, Sweden, France, Israel and Switzerland. It involves a 'presumed consent $\gg$ polic[y], where physicians can take required tissuesc and organs unless either the deceased carries a cardos to prohibit this, or the next of kin object' (5). It $\vec{\bullet}$ therefore places the burden of decision on the indi- -0 vidual, who is required to make a conscious effort $g 8$. opt out of the scheme if $\mathrm{s} / \mathrm{he}$ wishes to do so.

\section{Hint of coercion}

Mason and McCall Smith suggest that this policy 'smacks of "body-snatching" and carries with it a $\overline{\overline{0}}$ hint of coercion ... [and they] cannot foresee a 3 British government risking such a major policy change' (6). Although I do not disagree with their conclusion, it is worth being clear what exactly is coercive about such a scheme.

The notion of consent, properly voluntary and $\overline{3}$ adequately informed, is absolutely central to modern medical ethics, and readers of the journal will not $\frac{3}{3}$ need to be reminded of its salient features. But it is worth reminding ourselves that 'the notion under-? lying "giving one's consent" is "feeling together" $-\frac{7}{0}$ that is "agreeing" and hence "giving approval or permission"' (7). In the increasingly abstruse discussion $N^{\circ}$ of informed consent, it is easy to lose sight of the factr that underlying the whole question is the notion of agreeing - of deciding together. Given that the notion ${ }_{\sigma}^{\omega}$ of agreement between is internal to the idea of consent, it is clear why true consent cannot go by응 default: we cannot assume that in the absence of anyos contra-indications, a brainstem dead patient would ${ }_{T}$ not have minded his/her organs being removed foro transplant. If consent is as important to the ethical疋 practice of medicine as it is held to be, then an opt-out scheme is not a possibility.

It may of course be that an individual's wishes are held to be irrelevant in the face of the public good, 
and that the general utility would be promoted by the removal of cadaveric organs without express permission, but that is another matter entirely. Utilitarian considerations of the problem of the shortage of potential donor organs, as Harris has shown, give very different - and often strikingly counterintuitive - results (8).

\section{Market in organs}

The other solution to the drastic shortage that is conventionally proposed, usually but not exclusively as a thought experiment (9), is to create a market in organs. The purchase of organs from live donors has yet to be legalised, although the practice is by no means unknown (10) and proposals to allow cadaveric organs to be purchased have so far failed to be realised. But once a demand among the rich has been identified and the means to satisfy that demand devised by the poor, it becomes increasingly difficult to stop the development of a market. It is therefore imperative to be absolutely clear whether that market is an acceptable one or not before it gains a foothold.

Since 1989, the sale of organs has been outlawed in Britain by the Human Organ Transplants Act, in line with the principle of English common law that the body is not to be treated as property. Abouna et al considered the notion of paid organ donation and found it to be

'a flawed, short-sighted, and self-defeating approach to a complex problem. Paid organ donation has a serious negative impact on many of the medical, moral, and ethical values intimately connected with organ transplantation including the donor, the recipient, the local transplant programmes, the medical profession, society, and the international community' (11).

The problems with paying live donors for organs are too well known to rehearse in any great detail here, but mainly concern danger to, and exploitation of, both donor and recipient in the face of commercial pressures, and a fall-off in voluntary donation. These undesirable consequences are in addition to the conceptual problems concerned with treating the body or its parts as property.

\section{Paying next of kin}

A variant of the policy is sometimes proposed, which advocates paying the deceased donor's next of kin (12). Although this avoids the problem of danger to the donor, a moment's reflection reveals that it is even less attractive an option than paid donation from live donors. Not only are the same conceptual difficulties present, but

'the selling of cadaver organs is, at root, directed to the enticement of the next of kin. Put this way, the proposition can only be seen as appealing to the basest of human instincts and as something with which the medical profession should have no truck' (13).

As lawyers from the city where Burke and Hare once plied their horrid trade, Mason and McCall Smith are only too well aware of what lies at the bottom of this particular slope.

Allied to this suggestion is the notion of 'required request' which has been embodied in federal law in the USA since October 1987, whereby physicians are obliged to ask the relatives of suitable deceased patients for permission to harvest organs for transplant. This policy seems objectionable for two reasons. Firstly, and most importantly, it makes the wishes of the surviving relatives determinative rather than those of the individual whose organs are being sought; secondly, it risks creating the impression in the minds of the relatives that a patient's ventilation is being discontinued simply because his/her organs are needed by somebody else, thus eroding trust in the intensivists.

It should also be clear that our pre-reflective notions of justice are outraged by the possibility of a market in donor organs. The NHS is founded on a principle of equity of access to care irrespective of income or wealth, and this is hardly likely to be served by establishing a means by which the already limited supply of donor organs for transplants can be further diminished by financially enabled queue-jumping.

\section{IV.}

If these traditional solutions to the problem fail, then what more can we offer? Or is there nothing more that we can do except commission bigger and louder advertisements exhorting the public to carry donor cards? Before we can answer that question, we need to have an idea of the sort of answer we are looking for. I suggest that there are six desiderata of any proposed solution.

Firstly, and most obviously, any putative solution must address the problem of shortage by better matching supply of donor organs to demand for them. This might be achieved either by increasing the supply, for instance by a successful campaign to encourage donation, or by reducing the demand by, for instance, the development of acceptable alternative therapies (14).

Secondly, the solution must satisfy the requirements of justice, which I glossed above, following Aristotle, as treating only those cases that are relevantly dissimilar in different ways.

Derived from this general condition but specific to current understandings of health care provision in Britain, no individual should be excluded from the transplant programme on the grounds of inability to pay for the treatment. As I argued above, this condition rules out the creation of a market in donor organs. 
Fourth, in accordance with our conception of the individual as a rational free agent, our putative solution should be founded in an autonomous choice. Although it would be easy (in theory) to ensure an adequate supply of donor organs if no account were taken of individuals' wishes - by Harris-like selected sacrifice, for example - our basic intuitions about the place of autonomy in our lives rules out such coercive practices. It can, of course, be argued that all laws are in some measure coercive, and that therefore any legislative solution to the problem will inevitably infringe the autonomy of some. Notwithstanding this, in a liberal society coercion, particularly over a matter as important as bodily integrity, is to be shunned.

Although the fifth condition is not central in the way that the first four are, it nonetheless seems desirable in a solution that should address the problem of the free rider. Of course, if a proposal can be tabled that appears to fit the other desiderata but still allows some individuals to benefit from, without participating in, the scheme, then we would not on those grounds alone reject it. Even so, a solution that eliminates the possibility is to be preferred to one that does not, ceteris paribus.

Finally, and equally non-centrally, it would be desirable although in no way necessary, if the solution were to encourage altruism.

\section{V.}

I now turn to another possible solution to the problem which I shall outline briefly and examine with these desiderata in mind. It is worth noting in passing that this solution relies on a decision that takes place behind a Rawlsian veil of ignorance, and might therefore be presumed to yield a prima facie just result.

I suggest that legislation governing organ donation be amended such that all and only those who identify themselves as potential donors (perhaps by a card similar to the one currently in use, or by registration on a central computer) are eligible themselves to receive transplant organs (15).

It will be immediately apparent that this solution is a form of the closed, co-operative agreement beloved of social contract theorists: that is, its members receive a benefit in return for the agreed, mutual sacrifice of one or more of their interests. That is the positive side of the contract, as embodied by the principle that all those who participate stand to benefit. The negative aspect of exclusion is captured in the condition that only those who undertake to sacrifice their own interests are eligible for the benefits.

\section{Thoroughly attractive option}

This is a particularly compelling example of a social contract, however, because of an unusual feature.
Many hypothetical contracts focus on the trade-off $\frac{c}{2}$ between two interests that are seen as mutually $\stackrel{\mathrm{m}}{\mathrm{m}}$ exclusive (standardly, my - presumed - wish to rape $\vec{\Sigma}$. and pillage and my own desire for the security to be $\bar{\varnothing}$ free from being myself raped and the victim of $\Rightarrow$ pillage). This contract, however, trades a - if not the $\stackrel{?}{+}$ - central interest, one's interest in remaining alive, 음 against one's post mortem interest in not having one's organs removed. This latter is at best de minimis: my $\frac{\bar{T}}{\overrightarrow{0}}$ interests in my organs after death can hardly be said $\stackrel{\mathbb{Q}}{\square}$ to be enormous. We are presented, then, with what $ळ$ seems to be a thoroughly attractive option: by sacri- $\vec{\theta}$ ficing our minimal post mortem interests we guarantee our inclusion on the waiting list for the donor $\vec{\omega}$ organ which might save or vastly improve the quality $\stackrel{S}{?}$ of our own life. That is, we make possible the satis- $\bar{\oplus}$ faction of our own most compelling interest by renouncing one which is of little or no concern to us.

Adoption of this scheme would, I suggest, address the problem of shortage on two fronts simul- $\mathscr{E}$ taneously. Firstly, by excluding those who do not 을 elect to join the scheme, it will reduce legitimate demand for donor organs. It should be noted that $\geq$ the reduction thus effected will probably be minimal, which is surely a good thing, in that it क seems preferable that supply be better matched to $\vec{\theta}$ demand by increasing supply rather than by elimis $f$ nating or reducing demand.

Secondly, and more importantly, the supply donor organs would at the same time increase as result of an upturn in the number of registered potential donors. It hardly seems fanciful to suggest that the vast majority of people would elect to join the scheme, since it is so clearly in their interests to do so, with the potential gain (life) being infinite and the potential loss (post mortem dissection which, depending on the manner of their death, they might well have to undergo anyway) being zero. Unlike the 'survival lottery' proposed by Harris, nobody is going to be sacrificed in order to save others. Under 3 this scheme, the potential for benefit and loss is separated by the moment of death: only benefits can accrue to the living, and losses - if it makes sense to speak of post mortem losses - can only occur after death.

The proposed scheme appears to satisfy the requirements of justice, in that differences in access $\mathcal{N}$ to a particular treatment are grounded in relevant $N$ considerations, and those and only those who elect $N$ potentially to contribute to the system stand to benefit from it. In this way the problem of the free rider is eliminated by the exclusion of those who do not - at least potentially - contribute.

The contract scheme would also have the (marginal) benefit of promoting - albeit self-regarding - altruism, which is taken to be a morally desir- $\mathbb{\otimes}$ able end in and of itself. Moreover, this alignment of $\frac{}{\mathbb{D}}$ the individual's self-regarding interests with the $\varrho$ public good is a strength as far as the scheme's likely successful implementation is concerned. Given a 
moderate version of the social contract theorist's premise, that people tend to act in what they perceive to be their own best interests, it follows that a scheme under which acting in one's best interests is concomitant with, and necessarily entails acting in, the best interests of the population at large will inevitably tend to promote the public good.

Conceptual, ethical and aesthetic problems arising from the commercialisation and objectification of body parts are avoided since the scheme makes no reference to money or any market principles. Similarly, since there is no question of purchasing organs, there is no danger of individuals being excluded from a transplant programme on the grounds of their inability to pay. Nor, moreover, is there the financial inducement to sell organs as a live donor in order to alleviate financial hardship.

Finally, the proposal seems no more coercive than any other arrangement which offers a valued future goal as a reward for some sacrifice. Indeed, the coercion involved looks to be particularly thin, given that all the benefits accrue to the individual while $\mathrm{s} / \mathrm{he}$ is alive while the costs are exacted exclusively after his/her death. The responsibility to register as a potential donor - and therefore as a potential recipient - rests with the individual alone. Voluntary exclusion, therefore, is a real possibility, although it would carry with it obvious costs. But the choice remains a real one.

\section{VI.}

The scheme seems to me to be self-evidently in the interests of all of us jointly and each of us severally. However, it is worth pointing out that there is one possible injustice that could arise from its successful implementation. Imagine that ten years hence, the registration scheme has been adopted and has been found to be a success. Transplant specialists are now no longer restricted with respect to their choice of recipients by the availability of donor organs, but by medical criteria. In fact, so successful has the scheme been in encouraging voluntary cadaver organ donation, that there is a surplus of organs suitable for transplant: more hearts, lungs, kidneys and livers are being donated than are required to transplant into those individuals registered as potential donors, who are the only ones who have a legitimate claim on them.

Imagine also that there are a number of people outside the registration scheme who objected to, balked at, or simply never got around to registering as potential organ donors. A certain percentage of these people will suffer renal failure, or develop cardio-pulmonary conditions that could be alleviated by a transplant. But, because of their failure to join up, they have no legitimate claim on the - available - donor organs. They would be dying only because of an inflexibility in the law.

I think this situation would indeed offend our sense of justice. We would be right to be sickened if it were to come about. But this does not show that the scheme is at fault, merely that it may, if it is very successful, need to be flexible in its implementation. Perhaps it would be fairer to say that those who register as potential organ donors will be given first refusal on any organ available for transplant. Perhaps there is another proviso that could be added. That seems a matter for the legal draftsman, and not the philosopher.

But note that the kind of injustice that we are considering here arises from an over-supply of donated organs, rather than the shortage that is the status quo. If this is a kind of injustice (and I suggest that it is easily avoided in the manner I have sketched above) then it is a very different sort from the one we have presently. And it is not only different, but considerably less offensive.

\section{Acknowledgements}

I would like to thank the two anonymous reviewers for their helpful comments on an earlier draft of this paper.

Rupert Farvis, $M A$, is Research Fellow in the Centre for Philosophy and Health Care, University College of Swansea, Singleton Park, Swansea.

\section{References and notes}

(1) West R. Organ transplantation. London: Office of Health Economics, 1991: 10.

(2) One of the remarkable features of transplant surgery that makes resource allocation in this field such a compelling problem is that the opportunity costs of any decision are clear and immediate. If $\mathrm{Mr} \mathrm{McHenry}$ and $\mathrm{Mr} \mathrm{McTavish}$ both need the same donor heart which is of a particularly rare blood group and weight - in order to survive beyond the end of the year, then the surgeon knows, even as s/he is saving $\mathrm{Mr}$ McHenry's life in the operating theatre, that $s /$ he is in all likelihood - depriving Mr McTavish of his last chance. Unlike many fields of health care resource allocation, where one Positron Emission Tomography (PET) scan represents an opportunity cost of so many theoretical, anonymous, hip replacements, in transplant surgery the cost can be traced to one particular individual.

(3) See reference (1): 9.

(4) Ethnic origin may become a relevant medical factor where tissue matching is dependent on it. In such a case, however, since the difference is a relevant one, it justifies discrimination on those grounds.

(5) See reference (1): 7.

(6) Mason J, McCall Smith R. Law and medical ethics [3rd ed]. London: Butterworths, 1991: 312.

(7) Ayto J. Bloomsbury dictionary of word origins. London: Bloomsbury, 1990: 132.

(8) Harris J. The survival lottery. Philosophy 1975; 50: 81-87.

(9) Cohen $L$. The ethical virtues of a futures market in cadaveric organs. In: Land W, Dossetor J. Organ 
replacement therapy: ethics, justice, commerce. Berlin: Springer Verlag, 1991: 302-310.

(10) See reference (9): 164-172.

(11) See reference (9): 165.

(12) Pliskin J. Cadaveric organs for transplantation: is there a need for more? Fournal of forensic sciences 1976; 21: 83.

(13) See reference (6): 313

(14) The implantation of an entirely artificial mechanical heart into Arthur Cornhill at Papworth Hospital in August 1994 provides some hope that such alternatives may no longer be the reserve of science fiction. We may be moving forward from the time when 'the artificial heart is ... only seen as a bridge until a $\frac{\widehat{D}}{2}$ suitable donor can be found'. (See reference (1): 12.)

(15) Note that 'being eligible to receive' does not necessarily entail 'will receive'. Obviously, any eligibility will be subject to suitable organs being available. Moreover, there is a case for applying a risk/benefit assessment even within the contractual scheme. However, as I argued above, any such assessment would be useful only to order a waiting list, not to govern admittance to it. Simple application of risk/benefit analysis is inadequate to resolve rationing problems.

\section{News and notes}

\section{First European Forum on Quality Improvement in Health Care}

The first European Forum on Quality Improvement in Health Care will be held at the QEII Conference Centre, London from the 7th to the 8th of March 1996. The forum will consist of plenary lectures, parallel seminars and workshops and discussions and short educational courses.

For more information contact: Clare Moloney, BMA Conference Unit, BMA House, Tavistock Square, London WC1H 9JP. Fax: 0171383 6663; tel: 0171 3836478. 